\title{
Why we need to reassess the sustainability of aging populations
}
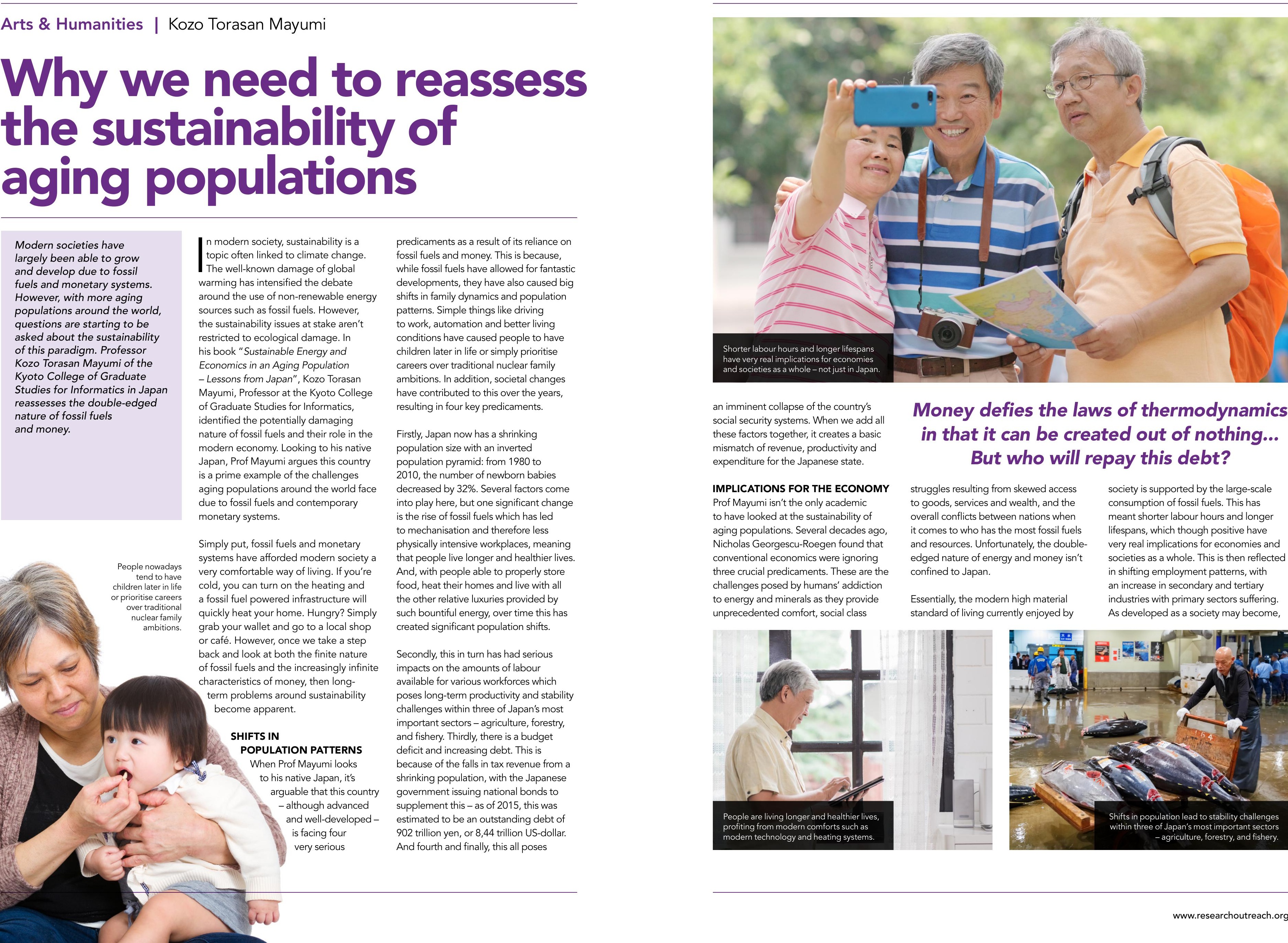

an imminent collapse of the country's social security systems. When we add all these factors together, it creates a basic mismatch of revenue, productivity and
expenditure for the Japanese state.

Money defies the laws of thermodynamics in that it can be created out of nothing... But who will repay this debt?

IMPLICATIONS FOR THE ECONOMY Prof Mayumi isn't the only academic to have looked at the sustainability of aging populations. Several decades ago, Nicholas Georgescu-Roegen found that conventional economics were ignoring three crucial predicaments. These are the to energy and by unprecedented comfort, social provs

struggles resulting from skewed access to goods, services and wealth, and the overall conflicts between nations when it comes to who has the most fossil fuels and resources. Unfortunately, the double cis

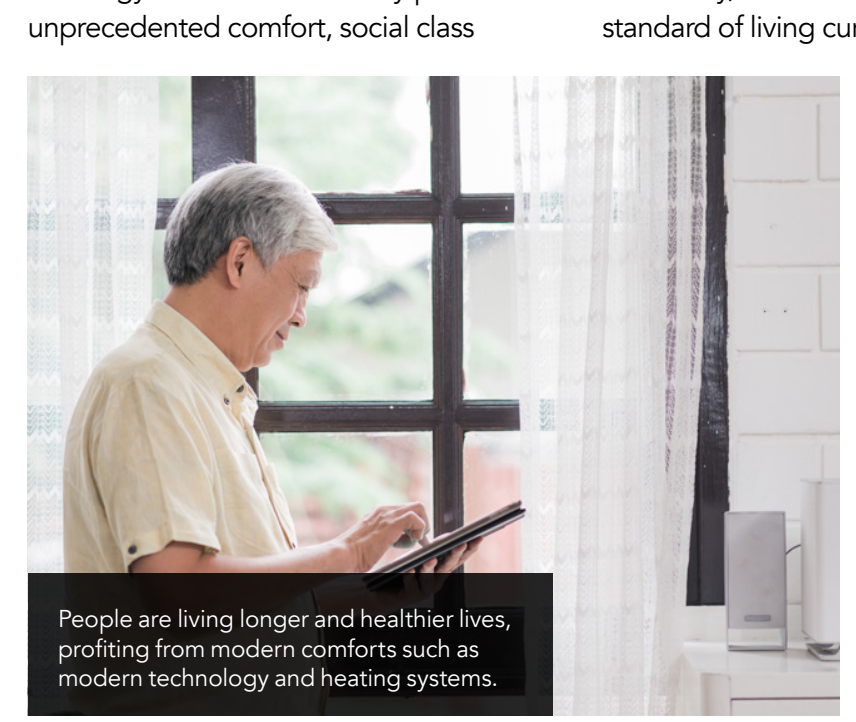

society is supported by the large-scale consumption of fossil fuels. This has meant shorter labour hours and longer lifespans, which though positive have very real implications for economies and societies as a hole. This is then reflected in shitting employment patterns, with industries with primary sectors suffering. As developed as a society may become. pest mortant sectors - agriculture, forestry, deficitend. Thilly, there is a budget because of the falls in tax revenue from shrinking population, with the Japanese supplement this - as of 2015, this was stimated to be an outstanding debt of And fount and finaly, this all poses

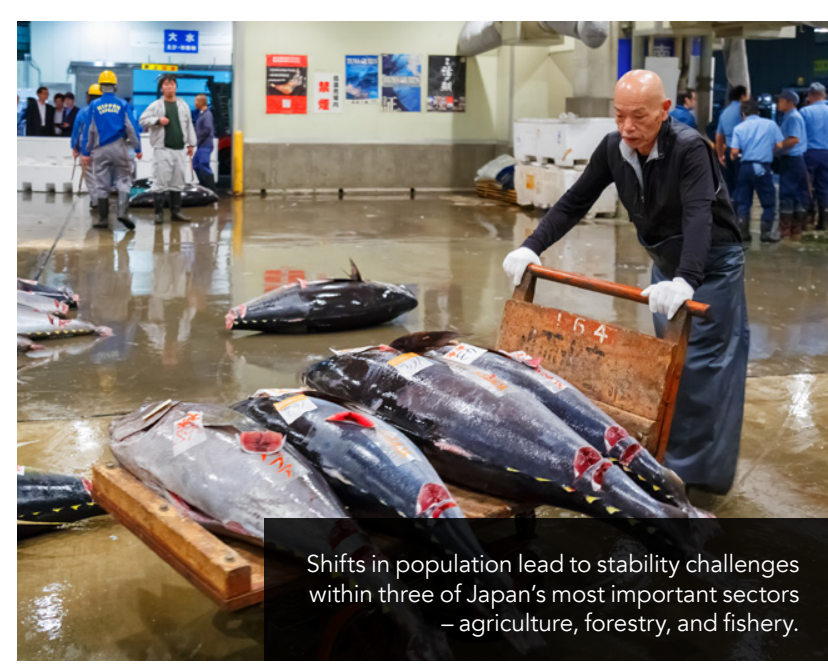


there will still be a need for agricultural workers, maintenance staff, raw material back to Japan, the number of primary workers in the tapanese economy in

1952 made up $46 \%$ of the countr's entire workforce. Fast fonward to 2010 and this was just $4 \%$

\section{A BIOPHYSICAL DEB}

At the same time, monetary systems have played a significant role. It's important to point out that money defies both the first and second laws of thermodynamics in that it can be created out of nothing and grow at a positive rate of interest. In effect, a perpetual motion machin is created. Money is made, spent, reinvested and then debt is issued. But who will repay this deb? Bluntly put, an aging population is predominantly not contributing to national productivity In many ways, money must theductivity. regarded as a biophysical debt from a communal perspective.

Here, it must be remembered that the most important principle of commerce is that a person - or nation - is only solven if there are immediately available credits at least equal to the amount of their

debts due and presented for payments. If the debts exceed the available credits, then this equilibrium is lost. There have been many critics of modern monetary policy over the years with som

economists divided on the real long-term impacts of this. Whatever the reality, with such huge amounts of money and debt to pay this back it's easy to see how the scales start to tip.

So, faced with such sustainability challenges what can modern society do? To get an idea of a potential way fonvard we could look to Prof Mario Giampietro of the Autonomous University of Barcelona and colleague of Prof Mayumi He has done a lot of work analysing the productivity and wastefulness of various energy sources. In particular, Giampietro has looked at both fossil fuel as well as nuclear and photovoltaic or PV systems (solar power to a layperson). His resear confirmed much of what activists have
long claimed, that as an energy source,

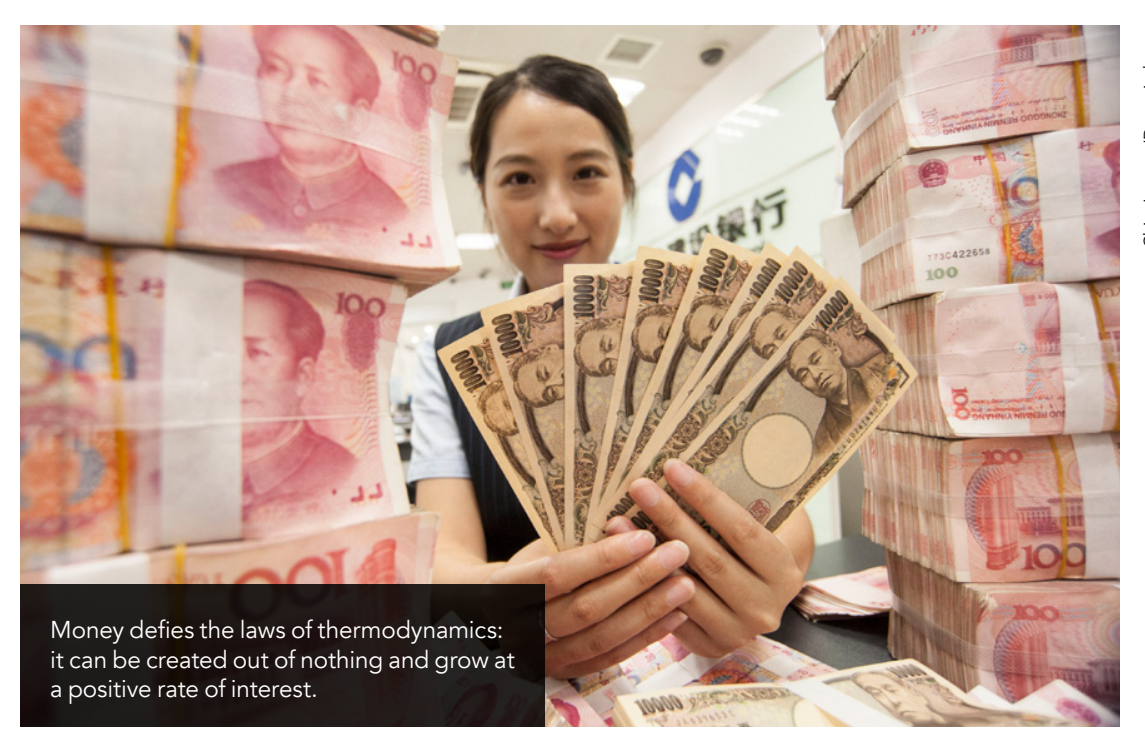

The well-established paradigm of fossil fuels and money means we - as a society - are more inclined to avoid these inconvenient truths.

PV systems require significantly less input of resources to produce electricity than

compared to nuclear energy and coel.

These findings are not necessarily confined to the academic world and it ching energy sources require greater attention. But here is arguably a problem, and this is quite simply that due to the wellestablished paradigm of fossil fuels and money we - as a society - are more truths (to borrow the interit ground-breaking 2006 docu Gore's

\section{TAKING THE RED PILL} In the 1999 film The Matrix, the
protagonist is asked whether or not he is willing to take the 'red pill' which is capable of showing him the painful yet What would the red pill show
us? Prof Mayumi concludes that society needs to
reevaluate fossil tuels.

true path to reality. The alternative is the 'blue pill' that allows him to remain immersed in blissful ignorance. Since then, the 'red pill' concept has come to symbolise the possibility of receiving a fresh view of something that was previously perceived as doctrine.

Based on the evidence Giampietro has provided around the credibility of nonrenewable energy sources, Prof Mayum concludes in his book that because he biophysical, socioeconomic, ossocicical policy are so deeply connected with each other, it's simply impossible to put these factors into conventional disciplinary fields. Therefore, faced with the very real risks created by agin populations, a new approach - no matter how inconvenient or initially difficult to swallow - is absolutely cessary in order to tackle sustainable gy policy and contemporary into context the painful but potentially very necessary need for energy and monetary reform for modern society, perhaps a red pill in relation to its viens

\section{Behind the Research}

Prof Kozo Torasan Mayumi

\section{Research Objectives}

Prof Mayumi studies the double-edged nature of fossil fuels and money and its predicaments for bioeconomics.

\section{Detail}

Kozo Torasan Mayum

The Kyoto College of Graduate Studies for Informatics Thanakamonzen

Kozo Torasan Mayumi is a Professor at the Kyoto College of Graduate Studies for Informatics. After 30 years'

involvement in energy analysis and bioeconomics, Mayum the last student of Georgescu-Roegen, is now working on the crucial role of both energy and money in relation to the sustainability of aging populations.

Collaborators

Mario Giampietro, Professor at Autonomous University of Barcelona

\section{keg.edu}

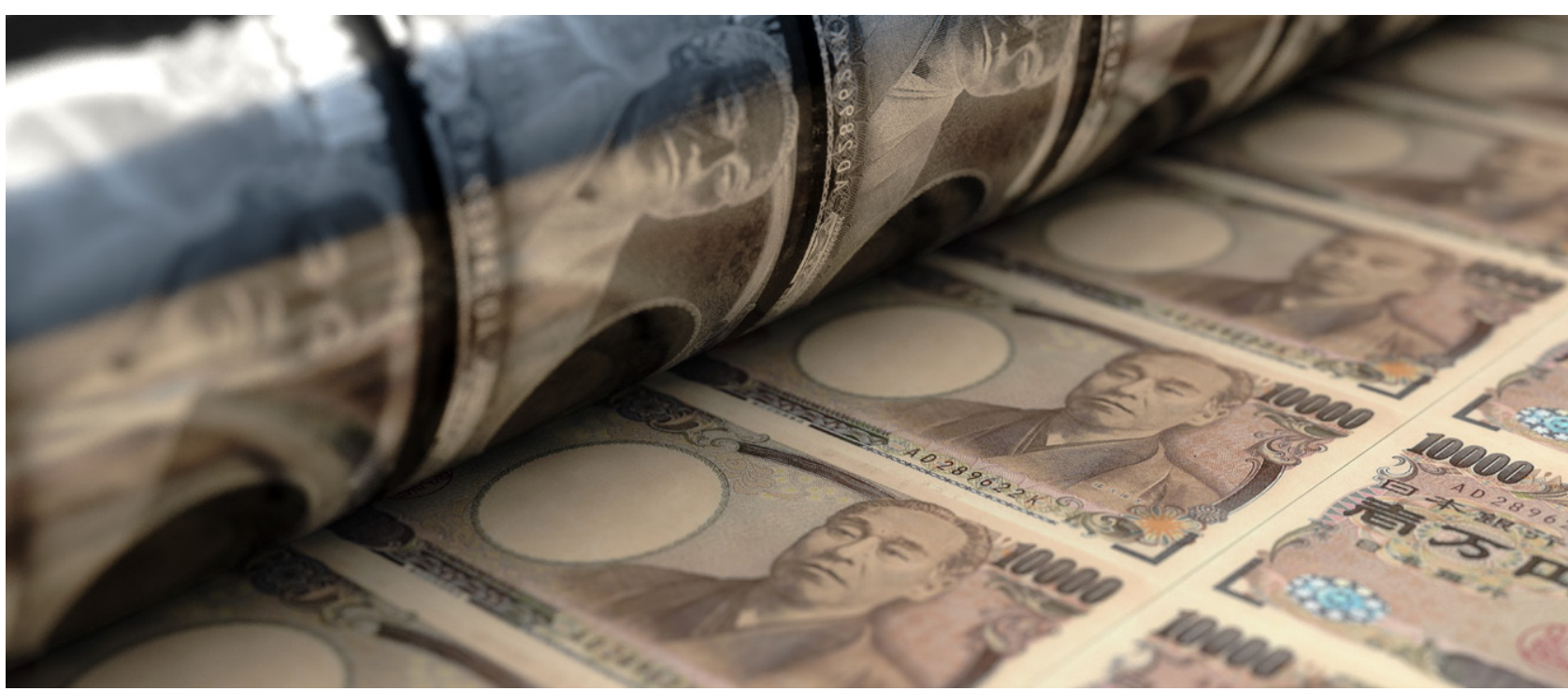

\section{References}

Diaz-Maurin, F. and Giampietro, M. (2013). A "Grammar" for assessing the performance of power-supply systems: comparing nuclear energy to fossil energy. Energy, 162-177.

Georgescu-Roegen, N. (1971). The entropy law and the

Mayumi, K.T. (2020). Sustainable Energy and Economics in A Agible at: htration - Lessons from Japan. Springer Nature

\section{Personal Response}

Aside from Japan, which other countries would you argue merit the above arguments? For predicaments being faced?

While Japan is an exemplar of the four bioeconomic Italy and the UK) are actually in the same situation due to the double-edged nature of the superiority of fossil fuels and monetary systems. In this way, both the biophysical debt and the monetary debt are disproportionately accumuling in the aging population, resuling in a more economic process. Cambridge, Massachusetts: Harvard 